\title{
The Use of Proton Pump Inhibitors and Prescription Pattern by Practicing Physicians at an Academic Hospital
}

\author{
Mohammed A. Basheikh, MBBS, ABIM Certified, FACP \\ Department of Internal Medicine, Faculty of Medicine \\ King Abdulaziz University, Jeddah, Saudi Arabia
}

\section{Correspondence}

Dr. Mohammed A. Basheikh

P.O. Box 80215, Jeddah 21589, Saudi Arabia

e.M: mbasheikh@kau.edu.sa

Submission: 25 June 2017

Accepted: 10 July 2017

\section{Citation}

Basheikh MA. The use of proton pump

inhibitors and prescription pattern by practicing physicians at an academic hospital. JKAU Med Sci 2017; 24 (4): 9-14. DOl: 10.4197/Med. 24.4.2

\begin{abstract}
The introduction of proton pump inhibitors has revolutionized the management of acid-related gastrointestinal disorders. Physicians use different regimen when prescribing proton pump inhibitors. In this study weaim to determine the prevalence and pattern of proton pump inhibitors prescription among practicing physicians at King Abdulaziz University Hospital in Jeddah, Saudi Arabia. A cross-sectional study was performed at different levels of doctors ranging from consultants to house officers from March-May 2014. The study included 85 doctors. The prevalence of proton pump inhibitors prescription was $57.65 \%$. Most of the respondents are internal medicine physicians with $58.62 \%$ ( 29 physicians) of them prescribing proton pump inhibitors. As well, half of the surgeons (24) were prescribing proton pump inhibitors. $54.17 \%$ of house officers who participated were prescribing proton pump inhibitors. Omeprazole at a dose of $20 \mathrm{mg}$ is the most commonly prescribed by $49.41 \%$, followed by the dose $40 \mathrm{mg}$ prescribed by $41.18 \%$. The rate of prescription for proton pump inhibitors at King Abdulaziz University Hospital with different specialties and levels is comparable to the practice worldwide. It's noted that house officers are prescribing proton pump inhibitors; they will need to be educated about the use, dosage, and side effects of proton pump inhibitors.
\end{abstract}

\section{Keywords}

Proton pump inhibitors; Prescribers; Prevalence; Academic hospital

\section{Introduction}

\footnotetext{
$P$ roton pump inhibitors (PPI) are one of the most frequently prescribed classes of drugs in the world because they combine a high level of efficacy with low toxicity. Proton pump inhibitors became widely available in the early 1990s, and they generally appeared to be superior to the histamine2-receptor antagonists in acid-suppressing activity, symptom control and healing.
}

Proton pump inhibitors are substituted benzimidazoles and are generally administered as enteric-coated tablets or capsules that pass through the stomach intact and are absorbed in the proximal small bowel. Once absorbed, all PPIs have a relatively short plasma half-life of 1-2 hours. Their duration of action is much longer because of their unique mechanism of action ${ }^{[1]}$. Most physicians now use proton pump inhibitors as a first-line treatment for many patients with acid-peptic disorders, including erosive gastro- 
esophageal reflux disease (GERD), non-erosive reflux disease (NERD) and duodenal and gastric ulcers ${ }^{[2]}$. Despite the widespread use of PPI therapy, physicians often dose these medications suboptimally ${ }^{[3,4]}$.

In this study we tried to survey how frequently and at what doses PPI is prescribed among health care workers at King Abdulaziz University Hospital, which is the largest teaching hospital in Jeddah.

\section{Method}

A secondary analysis of a cross-sectional study was performed to determine the knowledge and awareness about the use of PPI. The same questionnaire ascertained the prescribing patterns of proton pump inhibitors at different levels of practicing physicians at King Abdulaziz University Hospital (KAUH) in Jeddah, Saudi Arabia from March 2014-May 2014. We aimed to focus on the prescription pattern of oral PPI in the following specialties: internal medicine (IM), surgery, emergency medicine (ER), and obstetrics/gynecology (OB/GYN) departments. The departments that only prescribe PPI as intravenous (e.g., critical care) were excluded. Also excluded were the departments that did not have a dedicated ground rounds like ear-nosethroat (ENT) surgeons. The ground rounds for the concerned departments were targeted to distribute the questionnaire among the attendees, and the distribution was on a random sample in the concerned departments. We excluded pediatricians as they have different dosages for the pediatric patients compared to adult patients. The study included 85 doctors, ranging from consultants to house officers. The house officers are fresh new graduates from medical school, who are doing their mandatory year after graduation. The residency level is postgraduate in-training physicians at different levels of training. The specialists finished their training and are board eligible to be certified in either a major specialty or in a sub-specialty in the future. The consultants are those who finished their training and they are certified in a specialty or sub-specialty with a number of years' experience. The survey instrument which was a paper questionnaire consisted of the following variables: specialty, level of staff, PPI prescription, the usual oral dose for the routine prescription for GERD patients on their 1st presentation, and the PPI prescription for gastritis and esophagitis. Two questions we focused on in this study "have you ever prescribed PPI?" "what is the usual oral dose that you prescribe routinely for GERD patients on their 1st presentation?" Omeprazole that is set as example of PPI was written in the questionnaire, with example doses of $10 \mathrm{mg}, 20 \mathrm{mg}$, and $40 \mathrm{mg}$. The reason for this is because of the availability at KAUH pharmacy. To generate the results Microsoft Excel 2016 was the choice, and descriptive statistics were used to summarize the findings.

\section{Results}

\section{Distribution of Respondents According to their Answers}

\section{Specialty}

Table 1 shows that most of the respondents are "Internal Medicine" with $34.12 \%$ of total respondents. Surgery specialists represent $28.24 \%$ of the sample. The other specialties $\mathrm{OB} / \mathrm{GYN}$ and ER represent $7.01 \%$ together. Thirty percent $(30 \%)$ of the sample gave no answer, which they are house officers or general practitioners.

\section{Level of Medical Doctors Participated}

Table 2, house officers represent $28.24 \%$ of the sample. All years of residents training accounted for $48.24 \%$ of the sample. $11.76 \%$ were specialist.

\section{Have you prescribed PPI?}

Forty-nine of the respondents which represent $57.65 \%$ of the sample prescribed PPI, and 35 doctors which is $41.2 \%$ of the sample did not prescribe PPI. Only 1 $(1.17 \%)$ did not respond to this question.

\section{What is the usual Dose?}

The dose $20 \mathrm{mg}$ is the most commonly prescribed by $49.41 \%$ (42 doctors) from the total, and the dose 40 mg was prescribed by $41.18 \%$ (35 doctors). The least frequent dose is $10 \mathrm{mg}$ with a percentage $8.24 \%$ (7 doctors). One (1.17\%) did not answer.

\section{Differentiation Based on Specialty}

Table 3 showed that $57.65 \%$ of all specialty doctors had answered that they have prescribed PPI, $58.62 \%$ of Internal medicine and $50 \%$ of general surgery have also prescribed PPI. Only two ER physicians participated in the study and both had prescribed PPI.

\section{Discussion}

Ourstudy showed that more than half of the participants in the study representing different specialties from different levels at KAUH prescribed oral PPI. In addition to that most of the respondents are internal medical 
The Use of Proton Pump Inhibitors and Prescription Pattern by Practicing Physicians at an Academic Hospital M.A. Basheikh

Table 1. Distribution of respondents according to their specialties.

\begin{tabular}{|l|c|c|}
\hline \multicolumn{1}{|c|}{ Specialty } & Number of Participants & Percentage (\%) \\
\hline Medicine & 29 & $34.12 \%$ \\
\hline Surgery & 24 & $28.24 \%$ \\
\hline Obstetrics and Gynecology & 4 & $4.71 \%$ \\
\hline Emergency Room & 2 & $2.35 \%$ \\
\hline Not Answered & 26 & $30.58 \%$ \\
\hline \multicolumn{1}{|c|}{ Total } & $\mathbf{8 5}$ & $\mathbf{1 0 0 . 0 0 \%}$ \\
\hline
\end{tabular}

Table 2. Distribution of respondents according to their levels.

\begin{tabular}{|l|c|c|}
\hline \multicolumn{1}{|c|}{ Levels } & Number of Participants & Percentage (\%) \\
\hline Residents in First Year & 15 & $17.65 \%$ \\
\hline Residents in Second Year & 6 & $7.06 \%$ \\
\hline Residents in Third Year & 10 & $11.76 \%$ \\
\hline Residents in Fourth Year & 6 & $7.06 \%$ \\
\hline Residents in Fifth Year & 4 & $4.71 \%$ \\
\hline Consultant & 3 & $3.53 \%$ \\
\hline Specialist & 10 & $11.76 \%$ \\
\hline House Officer & 24 & $28.24 \%$ \\
\hline General Practitioner & 2 & $2.35 \%$ \\
\hline Not Answered & 5 & $5.88 \%$ \\
\hline \multicolumn{1}{|c|}{ Total } & $\mathbf{8 5}$ & $\mathbf{1 0 0 . 0 0 \%}$ \\
\hline
\end{tabular}

Table 3. Specialty versus Have you prescribed proton pump inhibitor.

\begin{tabular}{|c|c|c|c|c|c|}
\hline \multirow{2}{*}{\multicolumn{2}{|c|}{ Specialty }} & \multicolumn{3}{|c|}{ Have You Prescribed Proton Pump Inhibitor? } & \multirow{3}{*}{$\begin{array}{c}\text { Total } \\
29\end{array}$} \\
\hline & & \multirow{2}{*}{$\begin{array}{c}\text { Yes } \\
17\end{array}$} & \multirow{2}{*}{$\begin{array}{l}\text { No } \\
11\end{array}$} & \multirow{2}{*}{$\begin{array}{c}\text { Not Answered } \\
1\end{array}$} & \\
\hline Medicine & Count & & & & \\
\hline Medicine & $\%$ within Specialty & $58.62 \%$ & $37.93 \%$ & $3.45 \%$ & $100.00 \%$ \\
\hline \multirow{2}{*}{ Surgery } & Count & 12 & 12 & 0 & 24 \\
\hline & \% within Specialty & $50.00 \%$ & $50.00 \%$ & $00.00 \%$ & $100.00 \%$ \\
\hline \multirow{2}{*}{ Obstetrics and Gynecology } & Count & 3 & 1 & 0 & 4 \\
\hline & $\%$ within Specialty & $75.00 \%$ & $25.00 \%$ & $00.00 \%$ & $100.00 \%$ \\
\hline \multirow{2}{*}{ Emergency Room } & Count & 2 & 0 & 0 & 2 \\
\hline & $\%$ within Specialty & $100.00 \%$ & $00.00 \%$ & $00.00 \%$ & $100.00 \%$ \\
\hline \multirow{2}{*}{ General Practitioner } & Count & 2 & 0 & 0 & 2 \\
\hline & $\%$ within Specialty & $100.00 \%$ & $00.00 \%$ & $00.00 \%$ & $100.00 \%$ \\
\hline \multirow{2}{*}{ House Officer } & Count & 13 & 11 & 0 & 24 \\
\hline & \% within Specialty & 54.17 & 45.83 & $00.00 \%$ & $100.00 \%$ \\
\hline \multirow{2}{*}{ Total } & Count & 49 & 35 & 1 & 85 \\
\hline & \% within Specialty & $57.65 \%$ & 41.18 & $1.17 \%$ & $100.00 \%$ \\
\hline
\end{tabular}


physicians and more than half are prescribing PPI. Also, half of the surgeons were prescribing PPI to their patients.

The prevalence of PPI prescription was $57.65 \%$ and this percentage is within what has been published by other comparable studies, which is $30.4-66.6 \% \%^{[5-8]}$. In this study, most of the respondents who prescribed PPI are physicians or surgeons (59.18\% combined) which is comparable with other publications where they described the indication of prescribing PPI was mainly for internal, and postoperative medicines ${ }^{[0]}$. Regarding the level of the respondents, we noticed that house officers represent the major sector (28.24\%), which is a bit higher than what has been reported in the literature $(13.30 \%)^{[10]}$.

Regarding the prescribed dose, the PPIs $20 \mathrm{mg}$ and $40 \mathrm{mg}$ are the highest prescribed doses within the different doses (10-40 mg). It is reported that in general, a higher rate of relapse of symptoms was linked with lower doses of omeprazole ${ }^{[10]}$. This might be the reason that the $20 \mathrm{mg}$ and $40 \mathrm{mg}$ are the most common doses reported in our survey, which is similar to what has been shown before. However, the $10 \mathrm{mg}$ dose was not commonly used by participants in this study, this can be explained by the fact that pediatricians are the ones commonly using this small dose and none of the pediatricians participated in our study.

Most of the house officers who participated in the study had prescribed PPI. However, it is not clear if those house officers fully understand the possible side effects of PPI and the proper doses that should be prescribed according to the indication. One possible explanation for this high rate of prescription of PPI among house officers could be that the house officer is following an order of a senior staff to prescribe PPI. Now with the reports of the link between the use of PPI and dementia ${ }^{[11]}$, and other side effects. Specialty professional organizations recommend that people take the lowest effective dose possible to achieve the desired therapeutic result when using proton pump inhibitors to treat gastroesophageal reflux disease long-term ${ }^{[12]}$. In the United States, the Food and Drug Administration advises that no more than three 14-day treatment courses should be used in one year ${ }^{[13]}$.

Proton pump inhibitors were considered a safe medication to prescribe, but with the increasing new development of side effects and warnings in black box by the FDA with the use of clopidogrel, it is essential that we be more cautious in prescribing PPI. As it shows in our study that junior physicians are commonly prescribing PPI, we need to either limit the house officers from prescribing PPI or educate them enough about the proper uses and correct dosage of PPIs.

\section{Limitations}

Despite the efforts to include different prescriber categories including medical physicians, surgeons, OB/ GYN, and ER, one critical point that limits our study is that the overall response rate for the survey was low. Our results may thus underestimate or overestimate the overall prescription of PPI by doctors. Another limitation is the absence of linking between the different diseases grades and the prescribed doses.

\section{Conclusion}

The rate of prescription for PPI in this academic institute is the same as the practice worldwide. It's noted that house officers are prescribing PPIs; they will need to be educated about the use, dosage, and side effects of PPI. Future studies are needed to find out the differences in the pattern and frequency of PPIs prescription among academic and non-academic prescribers.

\section{Conflict of Interest}

The author has no conflict of interest.

\section{Disclosure}

The author did not receive any commercial or financial support for this study. The author has no financial interest in any of the products, devices, or drugs mentioned in this article.

\section{Ethical Approval}

Obtained.

\section{References}

[1] Wang M, Han X, Zhou Z. New substituted benzimidazole derivatives: a patent review (2013 - 2014). Expert Opin Ther Pat 2015; 25(5): 595-612.

[2] Juurlink DN, Gomes T, Ko DT, Szmitko PE, Austin PC, Tu JV, Henry DA, Kopp A, Mamdani MM. A population-based study of the drug interaction between proton pump inhibitors and clopidogrel. CMAJ 2009; 180(7): 713-718.

[3] Fass R. Proton pump inhibitor failure-what are the therapeutic options? Am J Gasteroentrol. 2009; 104: S33-S38 
[4] Sebastian S, Kernan N, Qasim A, O'Morain C, Buckley M. Appropriateness of gastric antisecretory therapy in hospital practice. Ir J Med Sci 2003; 172: 115-117

[5] Harris AW, Beveridge I, Dove-Edwin I, Keen J, Silk DBA, Misiewicz JJ. Audit of the use of anti-secretory drugs [abstract]. Gut 1997; 40(Suppl 1): A59.

[6] Jones MI, Greenfield SM, Jowett S, Bradley CP, Seal R. Proton pump inhibitors: a study of GPs' prescribing. Fam Pract 2001; 18(3): 333-338.

[7] Mayet AY. Improper use of antisecretory drugs in a tertiary care teaching hospital: an observational study. Saudi J Gastroenterol 2007; 13(3): 124-128.

[8] Lødrup A, Pottegård A, Hallas J, Bytzer P. Use of proton pump inhibitors after antireflux surgery: a nationwide register-based follow-up study. Gut 2014; 63(10): 1544-

[9] Alzahrani M, Al Ghamdi B, Al ahmari H, Algahtani E, Saleh A, Ahmed M. The Prescribing Pattern of Proton Pump Inhibitors by Non-gastroenterologists in a Tertiary Teaching Hospital in the Kingdom of Saudi Arabia. JAASP 2016; 1: 341-345.

[10] McDonagh MS, Carson S, Thakurta S. Drug Class Review: Proton Pump Inhibitors: Final Report Update 5 [Internet]. Portland (OR): Oregon Health \& Science University; 2009 May. Available at: http://www.ncbi.nlm.nih.gov/books/ NBK47260/

[11] Haenisch B, von Holt K, Wiese B, Prokein J, Lange C, Ernst A, Brettschneider C, Konig HH, Werle J, Weyerer S, Luppa M, Riedel-Heller SG, Fuchs A, Pentzek M, Weeg D, Bickel H, Broich K, Jessen F, Maier W, Scherer M. Risk of dementia in elderly patients with the use of proton pump inhibitors. Eur Arch Psychiatry Clin Neurosci 2015; 265(5): 419-28

[12] Fass R. Alternative therapeutic approaches to chronic proton pump inhibitor treatment. Clin Gastroenterol Hepatol 2012; 10(4): 338-345.

[13] Patel KA, Howden CW. Update on the diagnosis and management of Helicobacter pylori infection in adults. J Clin Gastroenterol 2015; 49(6): 461-467. 
المستخلص. لقد أدى إدخال مثبطات مضخة البروتون إلى إحداث ثُرة في إدارة اضطر ابات الجهاز الهضمي المرتبطة

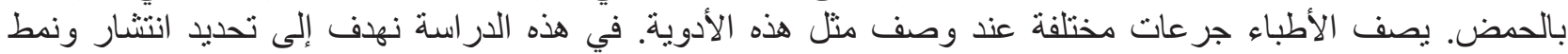

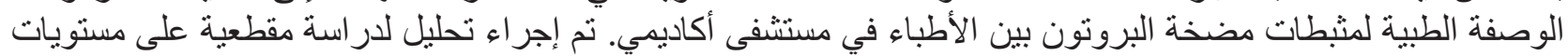

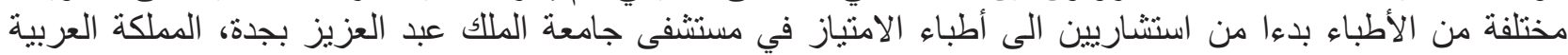

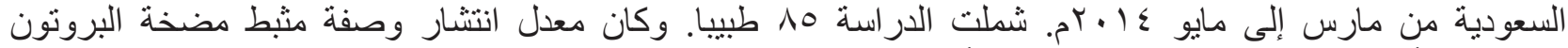

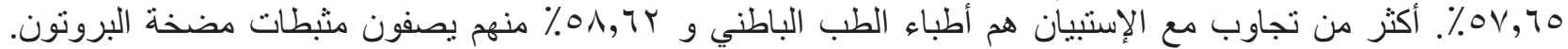

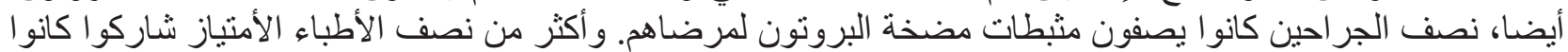

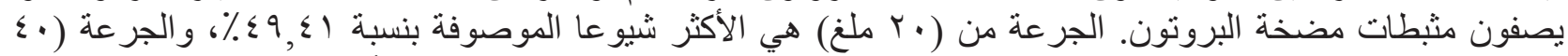

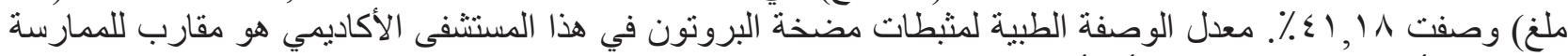

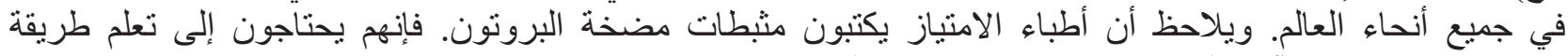

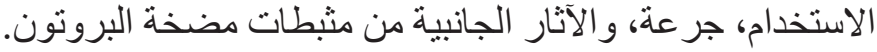

